\title{
TECNICISMO, TRABALHO E EDUCAÇÃO EM MARX
}

\author{
João Bosco Brito do Nascimento ${ }^{1}$
}

\begin{abstract}
Resumo:
O objetivo deste artigo é dissertar sobre o modo como Marx trata do processo da técnica no panorama contraditório da relação entre capital e trabalho. Vê-se, a partir dessa formulação, como o tecnicismo está presente na estrutura produtiva do capitalismo e como isto reverbera na educação escolar. Examina-se, conforme o pensamento econômico marxiano, como no processo do trabalho, peculiar ao regime do capital, a técnica e a tecnologia são derivativas desse processo. Há, deste modo, condições de inferirmos a vinculação entre a produção material e o sistema educacional nas sociedades capitalistas. O desenlace deste exame é a compreensão de que se tome a técnica, a tecnologia e a maquinaria enquanto condições que as remetem ao estudo do desenvolvimento histórico da produção capitalista. Neste diapasão, a classe dos trabalhadores está submetida aos ditames do tecnicismo do processo do trabalho. Destarte, o decurso da produção e reprodução da vida social é, em essência, antinômico. Às relações econômicas encerra-se a correspondência das formas ideológicas ou da superestrutura jurídica e política. A educação escolar, na sua forma patente de componente ideológico da sociedade, retroalimenta as condições materiais da produção. O Estado é o ente que tem a competência para mediar as necessidades instrumentais do aparato produtivo com o sistema institucional de ensino e educação. Há, no modo capitalista de produção, uma contradictio in adjecto, visto que ela é, essencialmente, social, já a apropriação é, contraditoriamente, privada. A educação corrobora esta estranha situação social, visto que impõe aos alunos um padrão disciplinar que interessa fundamentalmente à produção. Importa, aqui, uma nova contradição. Tanto os educadores quanto os educandos defendem, em importante medida, os seus próprios interesses. Logo, há de se considerar a luta política e o papel do sujeito históricorevolucionário - o proletariado. A educação se faz, assim, condição intelectual mínima para que a classe trabalhadora tome conhecimento da teoria marxiana, o que significa a posse da munição intelectual capaz de fazer plausível uma prática que busque a sua autoemancipação, na construção de uma sociabilidade genuinamente humana.
\end{abstract}

Palavras-chave: Marx. Técnica. Capital. Trabalho. Educação.

\section{TECHNICISM, LABOR AND EDUCATION IN MARX}

\begin{abstract}
:
The goal searched by this article is to evaluate how Marx deals with the process involving the technique within the conflicting scenario seen in the relationship between capital and labor. From this formulation, one can see how technicism is present in the productive structure of capitalism and how it resounds in school education. It is investigated, according to Marxian economic thought how, in the labor process, peculiar to the capital regime, technique and technology are seen as derivatives of this process. In this way, it is possible to infer the link between actual production and the educational system in capitalist societies. The outcome of this examination is the understanding that technique, technology and machinery are features conducive to the study of the historical development of capitalist production. Resonating in this frequency, the working class is subject to the rules of technicality in the labor process. Thus, the production course and the reproduction of social life is, in essence, antinomic. The economic relations hold the common features of ideological forms or of the legal and political superstructure. School education, in its obvious form, as an ideological part of society, validates the material conditions of production. The State is the competent entity to provide the instrumental needs of the productive apparatus with the educational system. In the capitalist mode of production, there is a contradictio in adjecto, since it is essentially social, whereas appropriation is, on the contrary, private. Education validates this strange social situation, since it imposes on students a disciplinary pattern that is of

1 Doutor em Educação pela Universidade Federal do Ceará - UFC. Mestre em Filosofia pela Universidade Federal da Paraíba - UFPB. Especialista em Filosofia Política pela Universidade Estadual do Ceará UECE. Graduado em Filosofia pela Universidade Estadual do Ceará - UECE. Professor do Curso de Filosofia da Universidade do Estado do Rio Grande do Norte - UERN. E-mail: boscobrito@uern.br.
\end{abstract}


fundamental interest to production. Here, a new contradiction is important. Both educators and learners defend their own interests to an important extent. Therefore, one must consider the political struggle and the role of a historical and revolutionary subject - the proletariat. Education thus becomes a minimum intellectual condition for the working class to become aware of Marxian theory, which means possession of an intellectual weapon capable of enforcing a practice that makes plausible its self-empowerment to build a genuinely human sociability

Keywords: Marx. Technique. Capital. Job. Education.

\title{
1. Introdução
}

\begin{abstract}
Um negro é um negro. Só em determinadas condições é que se torna escravo. Uma máquina de fiar algodão é uma máquina de fiar algodão. Apenas em determinadas condições ela se torna capital. Fora dessas condições, ela é tão pouco capital como o ouro, por si próprio, é dinheiro, ou como o açúcar é o preço do açúcar.
\end{abstract}

Karl Marx

O objetivo deste artigo é mostrar como Marx entende o processo da técnica no panorama contraditório da relação entre capital e trabalho, e, segundo nossa própria compreensão, de como isto é reproduzido pelo sistema educacional da sociedade civilburguesa (bürgerliche Gesellschaft). A necessidade de pensar a técnica e a tecnologia na sociedade hodierna é algo cada vez mais urgente, dada a presença daquelas no cotidiano da vida dos indivíduos, já no primeiro quartel do século XXI, demandando, portanto, à filosofia um tema inevitável ${ }^{2}$. Partindo deste entendimento, o nosso objetivo estará especificamente direcionado a examinar como, de acordo com o pensamento econômico de Marx, no processo de produção do capital, a técnica e a tecnologia são derivativas deste processo, e de como isto, conforme veremos, reverbera na educação. Nosso percurso expositivo se dá, basicamente, por meio de uma leitura imanente de importantes formulações desenvolvidas por Marx no livro primeiro d'O Capital (1867), bem como de algumas passagens dos Manuscritos Econômico-Filosóficos (1844), da obra Para a Crítica da Economia Política (1859), e das Instruções para os Delegados do Conselho Geral Provisório (1866), das quais nos valemos para referenciarmos teoricamente a nossa exposição sobre o que denominamos tecnicismo do processo do trabalho, além de fundamentar as nossas ilações autorais sobre como esse processo reverbera na educação escolar. Dessa forma, pretendemos evidenciar a vivacidade e atualidade do pensamento econômico e filosófico marxiano.

2 De acordo com a apresentação do GT da ANPOF "Filosofia da Tecnologia e da Técnica", disponível em: $<$ http://anpof.org/portal/index.php/en/gt-filosofia-da-tecnologia-e-da-tecnica>.

\begin{tabular}{|l|c|c|c|c|}
\hline Revista Dialectus & Ano 9 & n. 19 & Agosto-Dezembro 2020 & p. $93-113$ \\
\hline
\end{tabular}


Marx vê a técnica em sua relação com a ciência, o que implica a tecnologia enquanto teoria geral sobre as técnicas, ou qualquer técnica moderna e complexa. Contudo, o mais importante, aqui, é perceber que Marx, ao estudar a técnica, a tecnologia e a maquinaria, não as toma como totalidades em $\operatorname{si~mesmas~}^{3}$, mas, ao revés, remete-as ao estudo do capital na historicidade concreta do seu processo de produção, o que torna patente como o tecnicismo no processo de trabalho resulta da lógica estrutural do modo de produção capitalista que, necessariamente, é marcado pela oposição entre capital e trabalho.

Nesta medida, o que pretendemos é explicitar o fato de a sociedade capitalista apresentar um estado de criação e inovação técnica e tecnológica único, em toda a história. Veremos como o dinamismo desta sociedade tem suas origens nela mesma, não constituindo, como já dissemos, acima, em outras palavras, uma dinâmica autônoma. Do ponto de vista de Marx,

sendo pessoas independentes, os trabalhadores são indivíduos isolados que entram em relação com o capital, mas não entre si. Sua cooperação só começa no processo de trabalho, mas, depois de entrar neste, deixam de pertencer a si mesmos. Incorporam-se então ao capital. Quando cooperam, ao serem membros de um organismo que trabalha, representam apenas uma forma especial de existência do capital. Por isso, a força produtiva que o trabalhador desenvolve como trabalhador social é a produtividade do capital (MARX, 2006, p. 386).

Vale acrescentar, ainda, que

(...) a maquinaria aumenta o material humano explorável pelo capital, ao apropriar-se do trabalho das mulheres e das crianças; como confisca a vida inteira do trabalhador; ao estender sem medida a jornada de trabalho; e (...) seu progresso, que possibilita enorme crescimento da produção em tempo cada vez mais curto, serve de meio para extrair sistematicamente mais trabalho em cada fração de tempo, ou seja, para explorar cada vez mais intensivamente a força de trabalho (MARX, 2006, p. 476-479).

Através do tecnicismo do processo do trabalho, aumenta, cada vez mais, o controle absoluto que o capital exerce sobre o trabalhador. A massa do proletariado produtivo é forçada, ao sabor da evolução das novas técnicas e tecnologias, a adaptar-se aos

3 Marx não concebe a "técnica como dotada de uma estrutura em si e de uma autonomia absoluta", tal como acertadamente Artur Bispo (2014, p. 77) assinala. Mas, de acordo com a análise marxiana, a técnica e a maquinaria "são expressão do desenvolvimento do capital como uma totalidade social. Apenas no contexto dessa totalidade social os complexos parciais podem ser devidamente elucidados. É o mundo material que engendra as condições de possibilidades para que a ciência possa irradiar-se pelo mundo da economia e das relações sociais". (Id. ib. p. 77-78).

\begin{tabular}{|l|c|c|c|c|}
\hline Qevista Dialectus & Ano 9 & n. 19 & Agosto-Dezembro 2020 & p. $93-113$ \\
\hline
\end{tabular}


atuais instrumentos de produção, sob pena de a qualquer momento, como meras peças descartáveis, serem substituídas no processo produtivo. A subordinação à técnica, pelo proletariado, é uma composição peculiar no processo do trabalho no sistema do capital.

Na qualidade de analista e crítico do capitalismo (kapitalismus), Marx parte das condições deste sistema enquanto sociedade de classes, o que, para o autor, traduz-se sempre em exploração e em instabilidade quanto à reprodução de sua inevitável relação de hegemonia de classe. Ele vê, deste modo, o processo de produção e reprodução da vida social, em tais circunstâncias, como um processo, em essência, contraditório. David Harvey expõe uma chave de leitura certeira ao escrever:

E, em parte, baseará o seu apelo à transição para o socialismo na necessidade de curar as grandes irracionalidades que surgem da contradição explosiva entre o crescimento nas forças produtivas e nas relações sociais nas quais se baseia o modo de produção capitalista (HARVEY, 2013, p.183).

Neste diapasão, veremos, primeiramente, como o homem, enquanto trabalhador, está alienado à técnica e à tecnologia, na medida em que estas são apenas uma dimensão do capital $^{4}$. Em Marx, vamos encontrar o seguinte esclarecimento:

A indústria moderna nunca considera nem trata como definitiva a forma existente de um processo de produção. Sua técnica é revolucionária (...). Por meio da maquinaria, dos processos químicos e de outros modos, a indústria moderna transforma continuamente, com a base técnica da produção, as funções dos trabalhadores e as combinações sociais do processo de trabalho. Com isso, revoluciona constantemente a divisão do trabalho dentro da sociedade e lança initerruptamente massas de capital e massas de trabalhadores de um ramo de produção para outro. Exige, por natureza, variação do trabalho, isto é, fluidez das funções, mobilidade do trabalhador em todos os sentidos. Entretanto, reproduz em sua forma capitalista a velha divisão do trabalho, com suas peculiaridades rígidas. (...) Essa contradição absoluta elimina toda a tranquilidade, solidez e segurança da vida do trabalhador, mantendo-o sob a ameaça constante de perder os meios de subsistência, ao ser-lhe tirado das mãos o instrumental de trabalho, de tornar-se supérfluo, ao ser impedido de exercer sua função parcial; como essa contradição se patenteia poderosa na hecatombe ininterrupta de trabalhadores, no desgaste sem freio das forças de trabalho e nas devastações da anarquia social (MARX, 2006, p. 551-552).

O itinerário da nossa exposição do primeiro tópico deste artigo nos leva a uma seção que corrobora nossa elaboração inicial, ao procurarmos mostrar como o aparato

4 Conferir, também, ROMERO, Daniel. Marx e a técnica: um estudo dos manuscritos de 1861-1863. São Paulo: Expressão Popular, 2005, passim.

\begin{tabular}{|l|c|c|c|c|}
\hline Qevista Dialectus & Ano 9 & n. 19 & Agosto-Dezembro 2020 & p. $93-113$ \\
\hline
\end{tabular}


técnico e tecnológico no sistema capitalista está atrelado às suas relações sociais de produção.

Por fim, no terceiro tópico deste presente estudo, pretendemos tornar evidente que a educação, no tempo em que toma a forma de pedagogia do capital $^{5}$, mostra-se refém de um sistema que a condiciona a ser um instrumento decisivo na manutenção e reprodução de uma força de trabalho disciplinada e instruída a serviço do modo de produção capitalista.

Contudo, não podemos jamais desconsiderar os avanços do desenvolvimento histórico, a partir do crescimento econômico embasado nas inovações da técnica e da tecnologia. No entanto, sem deixar de considerar o que, a nosso ver, é o mais importante: como tais inovações impelem um tipo de educação que privilegiará sempre, mediante o modo de produção capitalista, a apreensão dos complexos produtivos de acordo com o emprego das novas tecnologias pelos trabalhadores, antes de sua formação humana integral. Neste sentido, ao caracterizar o desenvolvimento tecnológico como um dos elementos primordiais na afirmação da indústria moderna, Marx alega:

\begin{abstract}
A indústria moderna rasgou o véu que ocultava ao homem seu próprio processo social de produção e que transformava os ramos de produção naturalmente diversos em enigmas, mesmo para aquele que fosse iniciado num deles. Criou a moderna ciência da tecnologia o princípio de considerar em si mesmo cada processo de produção e de decompô-lo, sem levar em conta qualquer intervenção da mão humana, em seus elementos constitutivos. As formas multifárias, aparentemente desconexas e petrificadas do processo social de produção se decompõem em aplicações da ciência conscientemente planejadas e sistematicamente especializadas segundo o efeito útil requerido (MARX, 2006, p. 551).
\end{abstract}

Entrementes, a educação burguesa carrega consigo mesma a sua antítese, na qualidade de uma contradição inerente ao seu próprio métier, o qual tem por princípio um projeto civilizador ${ }^{6}$, mesmo que este seja um projeto de classe. Neste, ideologiza-se o processo educativo, incutindo nos educandos as ideias das classes dominantes. Porém,

5 Conforme expressão utilizada pelos professores CHAGAS, E. F. e QUEIROZ, F. J. C. em Da pedagogia do capital e de sua antítese: violência, (de)formação do trabalho e a luta pela formação humana, Dialectus, ano 3, n. 9, set./dez., 2016, p. 100-112.

6 Cf. por exemplo, BOTO, Carlota. Instrução pública e projeto civilizador: O século VIII como intérprete da ciência, da infância e da escola. São Paulo: Editora Unesp, 2017. Ainda por nossa vez, ampliamos a observação acima, afirmando que não entenderemos adequadamente o conjunto da obra de Marx, se não nos dermos conta de que o filósofo do trabalho tem como objeto a desvelar o processo civilizatório que culmina com a formação da sociedade civil-burguesa, a qual ele decide decifrar. Ver: NASCIMENTO, João Bosco Brito do. A violência na sociedade e na educação em Marx e Engels. Tese de doutorado. Fortaleza, UFC, Departamento de Educação, 2019. p. 87.

\begin{tabular}{|l|c|c|c|c|}
\hline Qenista Dialectus & Ano 9 & n. 19 & Agosto-Dezembro 2020 & p. $93-113$ \\
\hline
\end{tabular}


paradoxalmente, ao propor um projeto de formação técnica e intelectual aos jovens, o sistema de ensino burguês - conquanto relativo aos interesses dos proprietários privados dos meios de produção -, malgré eux, vê o sistema do capital compelido a conceder, assim, espaço à luta política, com a qual a classe trabalhadora tem a possibilidade de usar o contraditório em oposição ao adestramento social idealizado pela pedagogia burguesa.

Pretendemos, em conclusão, conforme os argumentos que desenvolveremos ao longo deste artigo, haver construído elaborações que mostrem ser possível a superação da alienação e da exploração dos trabalhadores, submetidos à ordem do capital, a qual tem como um elemento necessário a produtividade tecnicista do processo do trabalho. Como também ter deixado claro a imprescindível efetivação de um modelo educacional que privilegie a formação omnilateral ${ }^{7}$ dos indivíduos humanos, em concordância com a revolução social radical, através da "expropriação de poucos usurpadores pela massa do povo" (MARX, 2006, p. 977), na construção de uma sociabilidade genuinamente humana.

\section{A alienação do homem, enquanto trabalhador, pela técnica}

Marx pensa a alienação ${ }^{8}$ do homem, enquanto trabalhador, com base na ontologia. De acordo com nosso filósofo, a separação entre os produtores diretos, isto é, os trabalhadores e o produto, ou seja, os objetos do seu próprio trabalho, assim como de suas condições objetivas do trabalho, constituem um processo que transforma em capital os meios de produção e ao mesmo tempo submete os produtores, quer dizer, os trabalhadores, ao regime do salariato $^{9}$. Conforme analisado por Marx:

7 Segundo Marx: "O homem apropria-se do seu ser omnilateral de uma maneira omnicompreensiva, portanto, como homem total” (MARX, 1989, p. 196-197).

8 Ver o verbete alienação em MORA, Ferrater. Dicionário de filosofia - Tomo I (A - D) Trad. Maria Stela Gonçalves et. al. São Paulo: Edições Loyola, 2000.

9 O regime do "salariato" concerne ao assalariado, isto é, a quem trabalha mediante salário. Para Marx: "O que vai para o trabalhador sob a forma de salário é uma parte do produto por ele constantemente reproduzido. Na verdade, o capitalista paga-lhe em dinheiro, mas esse dinheiro não é mais do que a forma na qual se converte o produto do trabalho, ou, mais precisamente, uma parte dele. Enquanto o trabalhador transforma meios de produção em produto, seu produto anterior no mercado se transforma em dinheiro. É com o trabalho da semana anterior ou do semestre precedente que se paga o trabalho de hoje ou do semestre em curso. A ilusão gerada pela forma dinheiro desaparece logo que se considera a classe capitalista e a classe trabalhadora, e não o capitalista e o trabalhador isoladamente. A classe capitalista dá constantemente à classe trabalhadora, sob a forma de dinheiro, letras que a habilitam a receber parte daquilo que esta produziu e do qual aquela se apoderou. Mas o trabalhador devolve continuamente essas letras à classe capitalista, para receber a parte do produto dele mesmo, que lhe é atribuída. A forma mercadoria do produto e a forma dinheiro da mercadoria dissimulam a operação” (MARX, 2006, p. 662-663). E, o pior, “(...) o trabalhador recebe apenas a parte mínima e absolutamente indispensável do produto; precisamente tanto

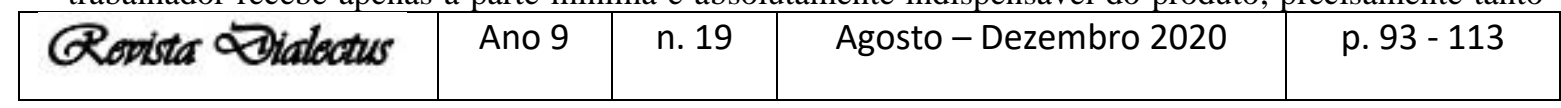


A separação entre o produto do trabalho e o próprio trabalho, entre as condições objetivas do trabalho e a força subjetiva do trabalho, é, portanto, o fundamento efetivo, o ponto de partida do processo de produção capitalista.

Mas o que no início é apenas ponto de partida torna-se, em virtude da mera continuidade do processo, a reprodução simples, o resultado peculiar, constantemente renovado e perpetuado, da produção capitalista. Por um lado, o processo de produção transforma continuamente a riqueza material em capital, em meio de expandir valor e em objetos de fruição do capitalista. Por outro lado, o trabalhador sai sempre do processo como nele entrou, fonte pessoal da riqueza, mas desprovido de todos os meios para realizá-la em seu proveito. Uma vez que, antes de entrar no processo, aliena seu próprio trabalho, que se torna propriedade do capitalista e se incorpora ao capital, seu trabalho durante o processo se materializa sempre em produtos alheios. Sendo o processo de produção, ao mesmo tempo, processo de consumo da força de trabalho pelo capitalista, o produto do trabalhador transforma-se continuamente não só em mercadoria, mas em capital, em valor que suga a força criadora de valor, em meios de subsistência que compram pessoas, em meios de produção que utilizam os produtores. O próprio trabalhador produz, por isso, constantemente, riqueza objetiva, mas, sob a forma de capital, uma força que lhe é estranha o domina e explora, e o capitalista produz constantemente a força de trabalho, mas sob a forma de uma fonte subjetiva de valor, separada dos objetos sem os quais não se pode realizar, abstrata, existente apenas na individualidade do trabalhador, em suma, o capitalista produz o trabalhador sob a forma de trabalhador assalariado. Essa reprodução constante, essa perpetuação do trabalhador é a condição necessária da produção capitalista (MARX, 2006, p. 665-666, o grifo é nosso).

Isto traduz a emergência, por um lado, da classe exploradora, a burguesia (proprietária dos meios de produção e de subsistência), no início do seu processo de classe hegemônica, quer dizer, mandante do processo de produção material e social. Por outro lado, há a mercantilização das relações de trabalho, compra e venda no mercado livre da mercadoria força de trabalho transformando os antigos servos ou camponeses em trabalhadores assalariados, depois destes terem sido espoliados, usurpados, roubados e expropriados dos seus meios de produção, em trabalhadores livres para serem explorados pelo capital, pelos capitalistas. Sendo que "o ponto de partida dessa nova relação social foi a expropriação material (objetiva) dos meios de produção" (ROMERO, 2005, p. 76).

Já nos Manuscritos Econômico-Filosóficos (1844), Marx explicita seus pressupostos:

Até agora, consideramos a alienação do trabalhador, só a partir de um aspecto, a saber, a sua relação com os produtos do trabalho. No entanto, a alienação não se revela apenas no resultado, mas também no processo da produção, no interior da própria atividade produtiva. Como poderia o trabalhador estar numa relação

quanto necessita para existir como trabalhador, não como homem, e para gerar a classe escravizada dos trabalhadores, não a humanidade" (MARX, 1989, p. 107).

\begin{tabular}{|l|c|c|c|c|}
\hline Qevista Dialectus & Ano 9 & n. 19 & Agosto-Dezembro 2020 & p. $93-113$ \\
\hline
\end{tabular}


alienada com o produto da sua atividade, se não se alienasse a si mesmo no próprio ato da produção? $\mathrm{O}$ produto da sua atividade, se não se alienasse a si mesmo no próprio ato da produção? O produto constitui apenas resumo da atividade, da produção. Por conseguinte, se o produto do trabalho é a alienação, a produção em si tem de ser a alienação ativa - a alienação da atividade e a atividade da alienação. $\mathrm{Na}$ alienação do objeto do trabalho, resume-se apenas a alienação na própria atividade do trabalho (MARX, 1989, p. 161-162, itálicos do autor).

Disto decorre que embora os indivíduos humanos se formem e se desenvolvam a si mesmos, agindo no mundo e o transformando através do trabalho, quando o produto do seu trabalho se lhe torna algo independente, e estranho ao próprio trabalhador, este mesmo passa a ser dependente, inferior e dominado, por assim dizer, escravo dos objetos, dos produtos do seu próprio trabalho. Então, os indivíduos, enquanto trabalhadores, tornam-se alienados às suas próprias ações vitais.

Mais ainda, como analisado por Marx, para que o trabalhador se encontre oprimido pelos produtos do seu próprio trabalho, é mister que o próprio ato da produção seja um ato alienado. $\mathrm{O}$ trabalhador, portanto, aliena a si mesmo, primeiramente, na própria atividade produtiva. Sob o capitalismo, a atividade vital dos indivíduos não expressa a manifestação da essência deles, pois o homem não trabalha voluntariamente, mas, em verdade, no modo de produção capitalista, o trabalhador é forçado a trabalhar. Sob o regime do capital, a atividade prática e vital dos homens não é expressão da sua vontade própria, mas, pelo contrário, tal vontade pertence a outrem, ao capitalista. $\mathrm{O}$ trabalhador labuta, enquanto produtor de mercadorias, para o mercado.

O resultado disto é que o trabalho, que, de acordo com a natureza mesma do homem, é a expressão da sua essência - sob o jugo dos interesses burgueses -, torna-se, ao mesmo tempo, responsável pela desrealização da essência humana. De fato, o homem, no trabalho, sente-se constrangido e violentado. Ele é, então, nesta condição, de acordo com Marx, transformado em mero animal, já que só se sente à vontade realizando funções puramente biológicas, tais como comer, beber e procriar, tomando-as de forma animalesca, enquanto finalidades últimas. Isto retrata, profundamente, uma degenerescência no comportamento dos indivíduos humanos ${ }^{10}$.

Deste modo, a autoalienação é, para Marx, mais precisamente, a alienação ${ }^{11}$ do trabalhador no ato da produção. Para simplificar, podemos dizer quer, sendo a vida do

${ }^{10}$ Ver: NASCIMENTO, João Bosco Brito do. A emancipação humana no jovem Marx: o Estado e a história. Dissertação de mestrado. João Pessoa, UFPB, Departamento de Filosofia, 1998. p. 86-88.

11 Neste artigo estamos considerando o conceito de alienação, em Marx, no sentido de um fenômeno negativo, sob o mesmo ponto de vista da tradição acadêmica marxista brasileira. Contudo, não desconhecemos que, de um lado, contemporaneamente, a alienação do trabalho, tem sido compreendida, por alguns importantes

\begin{tabular}{|c|c|c|c|c|}
\hline Rovista Dialectus & Ano 9 & n. 19 & Agosto - Dezembro 2020 & p. $93-113$ \\
\hline
\end{tabular}


homem a sua própria atividade, na relação entre o homem, como ser social, e o mundo exterior - o ambiente sociocultural e a natureza -, é próprio do indivíduo que ele seja autenticamente o sujeito do processo, visto que é neste processo que o homem busca transformar o mundo visando, satisfazer suas reais necessidades humanas. Contrariamente, na alienação da atividade, quando, como já assinalamos, a atividade pertence a outro e, por conseguinte, resume-se em sofrimento, está aprisionada uma ampla manifestação da verdadeira essência humana.

Some-se a isto que na atual fase do capitalismo, os trabalhadores veem-se cada vez mais achacados pela subordinação aos objetivos da acumulação do capital. Coagidos pela lógica da produção capitalista de mercadorias, os trabalhadores são obrigados a cumprir jornadas de trabalho cada vez mais exaustivas ${ }^{12}$.

A propósito, Marx alertara:

A partir do nascimento da indústria moderna, no último terço do século XVIII, essa tendência transformou-se num processo que se desencadeou desmesurado e violento como uma avalanche. Todas as fronteiras estabelecidas pela moral e pela natureza, pela idade ou pelo sexo, pelo dia e pela noite foram destruídas. As próprias ideias de dia e de noite desvaneceram-se (...). Eram as orgias do capital (MARX, 2006, p. 320).

O que pretendemos mostrar, ao longo deste tópico, é que a alienação enquanto prática da exteriorização, faz o trabalhador sucumbir aos interesses de um processo produtivo que são incompatíveis com as suas reais necessidades mesmas, visto ser um

teóricos marxistas, enquanto "um momento indispensável da objetivação", como assevera o professor Eduardo Chagas (1994, p. 28). Nesta perspectiva, Jesus Ranieri afirma que "na obra de Marx, diferentemente da forma trabalhada e consagrada pela bibliografia que tratou do tema, existe uma distinção entre alienação (Entäusserung) e estranhamento (Entfremdung)" (RANIERI, s/d, p. 1). Muito embora, os teóricos aqui referidos não deixem de reconhecer a importância, na teoria de Marx, de uma conceituação da alienação em seu sentido negativo, ou seja, como autoalienação (alienação negativa). Ver a importante contribuição à discussão dessa problemática oferecida por Eduardo F. Chagas em "Diferença entre alienação e estranhamento nos Manuscritos Econômico-filosófico (1844), de Karl Marx. Revista Educação e Filosofia, Uberlândia, UFU, v. 8, n. 16 p. 23-33. jul./dez. 1994. Ver também RANIERI, Jesus. Alienação e estranhamento: a atualidade de Marx na crítica contemporânea do capital. s/d. Disponível em:<http://biblioteca.clacso.edu.ar/ar/libros/cuba/if/marx/documentos/22/Alienacao\%20e\%20estranhame nto....pdf >. Acesso em: 05 mai./2020. Por outro lado, poderíamos aduzir, outrossim, além de argumentos favoráveis ao uso corrente de alienação no seu sentido negativo, as indicações de alguns renomados autores nacionais e internacionais que comungam e corroboram o uso negativo do conceito de alienação em plena sintonia com a fecunda análise marxiana. De sorte que optamos por nos nortear neste artigo, como já indicamos, pelo conceito de trabalho alienado. Todavia, embora não queiramos, no momento, entrar nesta seara de discussão, não a consideramos de importância menor. Daí a necessidade que reconhecemos de, ao menos, fazermos esta nota informativa ao leitor, no que se refere ao debate assinalado.

12 Ver também CORDEIRO, Sandra: "Marxismo, a filosofia insuperável do nosso tempo!", In: Trabalho, educação e a crítica marxista”. Fortaleza: Imprensa Universitária, 2006. p. 298-299.

\begin{tabular}{|l|c|c|c|c|}
\hline Renista Cialectus & Ano 9 & n. 19 & Agosto-Dezembro 2020 & p. $93-113$ \\
\hline
\end{tabular}


processo voltado para a produção de mercadorias - enquanto instituidora da forma social burguesa - que depende do trabalho produtivo requisitor de uma magnificência técnica e tecnológica, a fim de fazer frente às demandas do mercado mundial. É também imprescindível que consideremos, incontestavelmente, a condição de classe da sociedade capitalista, o que implica atentar para a gênese das suas relações sociais, que impulsionam as indispensáveis inovações da técnica e da tecnologia, a saber, a primazia da concorrência entre os capitalistas, advinda da fundamental oposição entre capital e trabalho, que é o sinete desta formação social.

\subsection{As relações sociais de produção capitalistas e o seu derivativo técnico}

As relações de produção só podem ser compreendidas em sua reciprocidade com as forças produtivas, pois essas configuram um binômio. Este, por sua vez, subjaz ao conjunto dos processos da sociedade ${ }^{13}$, não apenas ao econômico, mas também ao político e educacional.

Do mesmo modo, na produção das suas condições de existência, os homens estabelecem relações sociais que são mediadas pelo grau de desenvolvimento das forças produtivas, as quais independem da vontade daqueles. No capitalismo, a correlação entre as forças produtivas e as relações de produção implica - devido à necessidade de uma crescente produtividade no processo de trabalho para fazer frente aos interesses e necessidades do mercado mundial -, como já anunciamos, o imprescindível desenvolvimento do tecnicismo neste processo de trabalho, sendo que esta conduta impõe que os trabalhadores estejam escravizados ao instrumental técnico com o qual trabalham. Escrevendo de outra forma: no modo de produção capitalista, os trabalhadores estão sempre submetidos ao poder produtivo da técnica, enquanto agentes a serviço desta, ao invés de serem eles a manipularem-na conforme seus próprios objetivos - a isto chamamos tecnicismo do trabalho.

Leiamos Marx:

Graças ao progresso da produtividade do trabalho social, quantidade sempre crescente de meios de produção pode ser mobilizada com um dispêndio progressivamente menor de força humana. Este anunciado é uma lei na sociedade capitalista, onde o instrumental de trabalho emprega o trabalhador, e não este o

13 Cf. também o verbete "FORÇAS produtivas e relações de produção". HARRIS, Laurence. In: BOTTOMORE, Tom (Editor). Dicionário do pensamento marxista. Trad. Waltensir Dutra. Rio de Janeiro: Jorge Zahar Editor, 1988.

\begin{tabular}{|l|l|l|l|l|}
\hline Q Rovista Dialectus & Ano 9 & n. 19 & Agosto-Dezembro 2020 & p. $93-113$ \\
\hline
\end{tabular}


instrumental. Esta lei se transmuta na seguinte: quanto maior a produtividade do trabalho, tanto maior a pressão dos trabalhadores sobre os meios de emprego, tanto mais precária, portanto, sua condição de existência, a saber, a venda da própria força para aumentar a riqueza alheia ou a expansão do capital (MARX, 2006, p. 748).

Concluímos que estamos, aqui, examinando a manifestação de leis imanentes da produção capitalista, como estas se impõem coercitivamente na vida dos trabalhadores. Mas, desde o início deste artigo, procuramos deixar claro, para o leitor, que estamos municiados pelas elaborações marxianas enquanto análise científica rigorosa da forma social burguesa.

Então, buscando sempre o rigor científico, faz-se necessário, neste momento, chamar a atenção para o fato de que a elevação da produtividade do trabalho no capitalismo requer uma modificação no processo de trabalho baseado no desenvolvimento da técnica e da tecnologia e de uma correspondente transformação nas relações sociais do processo de trabalho, por meio das quais se encurta o tempo de trabalho socialmente necessário para a produção de mercadorias. Marx assinala:

É mister que se transformem as condições técnicas e sociais do processo de trabalho, que mude o próprio modo de produção, a fim de aumentar a força produtiva do trabalho. Só assim pode cair o valor da força de trabalho e reduzir-se a parte do dia de trabalho necessária para reproduzir esse valor.

Chamo de mais-valia absoluta a produzida pelo prolongamento do dia de trabalho, e de mais-valia relativa a decorrente da contração do tempo de trabalho necessário e da correspondente alteração uma relação quantitativa entre ambas as partes componentes da jornada de trabalho (MARX, 2006, p. 366).

Pode-se considerar que as duas partes componentes da jornada de trabalho são, primeiro, a parte necessária, na qual a própria força de trabalho se paga a si mesma, isto é, tem a sua manutenção supostamente assegurada com o recebimento do seu salário. A outra é a parte excedente, quer dizer, a mais-valia, que pode ser absoluta, quando é aumentado o tempo de trabalho e não se paga as horas excedentes ao trabalhador, ou relativa, quando a classe dos capitalistas consegue condições técnicas que venham a gerar uma produtividade mais intensa. Em ambas as partes da jornada de trabalho, acreditamos que se pode ver, com clareza meridiana, pelo que já expomos, como no modo de produção capitalista não há solução possível que interesse ao trabalhador, estando este permanentemente agrilhoado às leis férreas da lógica da produção que somente interessa aos detentores privados dos meios de produção, isto é, à classe dos burgueses capitalistas. O que faz perpetrar, sob este conjunto de fatores atuantes, a antinomia entre trabalho e capital.

\begin{tabular}{|l|l|l|l|l|}
\hline Qevista Dialectus & Ano 9 & n. 19 & Agosto-Dezembro 2020 & p. $93-113$ \\
\hline
\end{tabular}




\section{0 princípio tecnicista e tecnológico da educação com o fito de reproduzir capital}

Sabemos que estamos examinando a sociedade capitalista e pondo em relevo, conjuntamente, dois aspectos do seu funcionamento, quais sejam, o tecnicismo do processo do trabalho e o seu reverberar na educação escolar. Para tanto, faz-se necessário percebermos que não podemos deixar de tomar tal sociedade conforme esta é uma formação social. Isto quer dizer que o ser social é histórico: ele não nos é dado de uma vez por todas, pois não é eterno. Logo, a forma social burguesa, da qual estamos tratando, tem uma gênese e um processo, apresentando, por isto, um determinado movimento, desde os seus fundamentos até a sua completa conformação. Neste sentido, podemos afirmar que a sociedade capitalista ou, se assim quisermos, a forma social burguesa é uma totalidade, um todo eivado de múltiplas determinações.

Marx compreende que a sociedade capitalista tem uma base material - as relações econômicas - que ele denomina de infraestrutura e à qual se relacionam formas ideológicas ou uma superestrutura jurídica e política ${ }^{14}$. Assim, temos uma totalidade de múltiplas determinações que se correspondem reciprocamente, tendo a primazia das relações materiais.

Nesse sentido, o que fizemos no tópico anterior, foi tratar, mais especificamente, de alguns aspectos destas relações materiais - mais precisamente, do seu tecnicismo do processo de trabalho. Grosso modo, examinamos aspectos da produção material no modo de produção capitalista aos quais equivalem, como veremos aqui, elementos ideológicos que, particularmente, no nosso caso, referem-se à educação escolar, na medida em que esta constitui uma das sínteses da sociedade que é mediada pelo seu aparato jurídico político, a saber, o Estado. Este faz a mediação entre a estrutura econômica e produtiva da sociedade e os elementos que a retroalimentam, como se dá com a educação escolar.

Para Marx, a vida social humana, e não uma vida em geral, abstrata, é que determina a sua consciência ${ }^{15}$. O filósofo se posiciona no sentido de tematizar a concretude das relações sociais de produção das condições materiais de vida, para mostrar, com isto,

14 Cf. o prefácio de 1859 da notável obra de Marx Para a crítica da economia política, no qual ele nos dá o conceito de formação social.

15 Cf. também CHAGAS, E. F. “O pensamento de Marx sobre a subjetividade”. In: CHAGAS E. F. et. al. (Orgs.) Subjetividade e educação. Fortaleza: Edições UFC, 2012, p. 38.

\begin{tabular}{|c|c|c|c|c|}
\hline Rovista Aidectus & Ano 9 & n. 19 & Agosto - Dezembro 2020 & p. $93-113$ \\
\hline
\end{tabular}


como a consciência é construída. Não há, então, em Marx, uma consciência pura. Contudo, como já aludimos, e no que somos corroborados pela pertinente interpretação do professor Chagas, "ele não considera a produção material e a produção espiritual como dois momentos cristalizados, estáticos, mas sim como dois instantes que se operam ao mesmo tempo, como partes integrantes da totalidade social" (CHAGAS, 2012, p. 38).

Deste modo, a educação, enquanto uma das sínteses da sociabilidade do capital, que é organizada, dentre outros princípios, pelo tecnicismo do processo do trabalho e fundada na oposição entre capital e trabalho, interfere na formação dos educandos, usurpando-lhes suas mais autênticas e genuínas subjetividades humanas, ao impor-lhes padrões de comportamento e uma forma de conhecimento de interesse primordial do modo de produção capitalista.

Enfatizamos, então, na trilha do pensamento econômico de Marx, que nunca pensamos a educação em sentido abstrato, mas, antes, contextualizada, na sociabilidade do capital. Com isso, afirmamos que só podemos pensar a educação, ou dela tratar, dentro de um contexto histórico-social específico. Na sociedade capitalista a educação é unilateral, meramente tecnicista e/ou reprodutivista do sistema do capital.

Ao contrário, a educação que Marx propõe - isto significa que, embora ele não tenha uma obra ou um pensamento sistematizado sobre educação, podemos dizer que há uma teoria intrínseca de educação no seu escopo teórico e no arcabouço da construção do seu programa - é, antes de mais nada, uma educação universal ${ }^{16}$.

Mesmo quando Marx considera como um certo avanço o emprego da educação escolar para fortalecer a variação do trabalho no modo de produção capitalista, ele, em verdade, entende que isto, ou seja, a relação entre trabalho produtivo e educação é o mote para se pensar uma educação futura ${ }^{17}$, ideal para a classe trabalhadora, na forma de uma

16 De acordo com CHAGAS, Eduardo Ferreira. Marx e os seus textos sobre educação e ensino. Palestra proferida no VI Curso de Extensão: “A Filosofia da Educação: Uma Discussão a Partir da Tradição Filosófica”, UFC, 8 jun. 2018. Vejamos, aqui, a acepção precisa de Marx sobre o que seria o conceito adequado de educação universal: "Por educação entendemos três coisas: Primeiramente: Educação mental [intelectual]. Segundo: Educação física [corporal], tal como é dada em escolas de ginástica e pelo exercício militar. Terceiro: Instrução tecnológica, que transmite os princípios gerais de todos os processos de produção [e de caráter científico] e, simultaneamente, inicia a criança e o jovem no uso prático e manejo dos instrumentos elementares de todos os ofícios" (MARX, 1982, documento sem paginação, itálicos do autor, os grifos são nossos).

17 Segundo Marx, "do sistema fabril, conforme expõe pormenorizadamente Robert Owen, brotou o germe da educação do futuro, que conjugará o trabalho produtivo de todos os meninos além de uma certa idade com o ensino e a ginástica, constituindo-se em método de elevar a produção social e em um único meio de produzir seres humanos plenamente desenvolvidos" (MARX, 2006, p. 548-549).

\begin{tabular}{|l|c|c|c|c|}
\hline Revista Dialectus & Ano 9 & n. 19 & Agosto-Dezembro 2020 & p. $93-113$ \\
\hline
\end{tabular}


educação que possibilite a formação integral dos seres humanos. Dá-se isso porque a produção capitalista, ao contrário, exige, mediante as necessidades da autovaloração e expansão do capital, meramente uma maior capacidade do trabalhador para apreender novas habilidades, enquanto disciplina o seu caráter conforme o padrão necessário a um comportamento enquadrado ao sistema produtivo, algo que visa conseguir através do emprego da educação. Nesse sentido, Marx escreve:

\begin{abstract}
As escolas politécnicas e agronômicas são fatores desse processo de transformação, que se desenvolveram espontaneamente na base da indústria moderna; constituem também fatores dessa metamorfose as escolas de ensino profissional, onde os filhos dos operários recebem algum ensino tecnológico e são iniciados no manejo prático dos diferentes instrumentos de produção. A legislação fabril arrancou ao capital a primeira e insuficiente concessão de conjugar a instrução primária com o trabalho na fábrica. Mas não há dúvida de que a conquista inevitável do poder político pela classe trabalhadora trará a adoção do ensino tecnológico, teórico e prático, nas escolas dos trabalhadores (MARX, 2006, p. 553).
\end{abstract}

Nessa lógica, do ponto de vista que nos interessa, o estudo e a crítica da estrutura material do processo produtivo no regime do capital não é suficiente. Precisamos também mostrar como a educação é exercida com o fito de reproduzir e perpetuar a ordem do capital. Em Mészáros, por exemplo, vamos encontrar o seguinte esclarecimento:

\begin{abstract}
Assim, além da reprodução, numa escala ampliada, das múltiplas habilidades sem as quais a atividade produtiva não poderia ser realizada, o complexo sistema educacional da sociedade é também responsável pela produção e reprodução da estrutura de valores dentro da qual os indivíduos definem seus próprios objetivos e fins específicos. As relações sociais de produção capitalista não se perpetuam automaticamente. Elas só o fazem porque os indivíduos particulares "interiorizam" as pressões exteriores: eles adotam as perspectivas gerais da sociedade de mercadorias como os limites inquestionáveis de suas próprias aspirações (MÉSZÁROS, 1981, p. 260, itálicos do autor).
\end{abstract}

Logo, a educação institucionalizada, ao reproduzir um conjunto de ideias, regras e valores que preparam os jovens que servirão à máquina produtiva do capital, à maneira de formação de mão-de-obra, tem como uma das suas principais funções na sociedade capitalista ser reprodutora do sistema do capital ${ }^{18}$.

O sistema educacional burguês induz os alunos, desde a sua mais tenra idade, a aprenderem, e a reproduzirem as relações sociais de produção, através de instrumentos, tais quais, não somente o currículo, no qual tem-se a prevalência de conteúdos tecnicistas,

18 Ver também, a este respeito, BOURDIEU, Pierre; PASSERON, Jean-Claude. A reprodução: Elementos para uma teoria do sistema de ensino. 3. ed. Trad. Reynaldo Barão. Rio de Janeiro: Livraria Francisco Alves Editora S.A. 1992.

\begin{tabular}{|l|l|l|l|l|}
\hline Qevista Dialectus & Ano 9 & n. 19 & Agosto-Dezembro 2020 & p. $93-113$ \\
\hline
\end{tabular}


voltados para o aprendizado do manuseio das novas técnicas e tecnologias que servem à produção, mas também há a inculcação de todo um aparato ideológico que leva à sobrevalorização da disciplina do trabalho submetido à direção do salariato, tais como: autodisciplina; imposição da autoridade pedagógica; ação hierárquica: relações de hegemonia; obrigatoriedade do fardamento; reprovação por falta - a imposição da frequência obrigatória efetuada na forma da chamada; avaliação etc.

$\mathrm{Na}$ contramão da insistência ideológica da disseminação de padrões comportamentais que devem ser apreendidos pelos alunos como critérios de uma suposta formação para a vida - tema clássico nas filosofias burguesas da educação -, não nos escusemos de nos posicionar criticamente frente a tal procedimento, visto que, na atual sociedade de classes, o discurso que prevalece é o dos interesses do capital e, consequentemente, da classe dos capitalistas, como classe dominante econômica e politicamente.

Nos dias de hoje, os diversos sistemas técnicos e suas especificidades são estudados e apreendidos, sendo suas operacionalidades, no processo produtivo, destinadas ao controle dos interesses específicos das grandes corporações transnacionais. Deste modo, os trabalhadores são apenas peças parciais da máquina produtiva; como resultado, não dão conta do processo produtivo como um todo, mas, ao contrário, estarão, sob o sistema capitalista, sempre subordinados àquele.

Aqui, novamente se faz necessário reportarmo-nos ao Estado. Afinal, é este que regulamenta a política educacional através de uma legislação cuja finalidade é a produção e a reprodução do capital, sendo este destaque evidenciado no processo histórico de consumação da sociedade capitalista que, definitivamente, com a produção industrial e a consequente implantação do tecnicismo no processo do trabalho, estabelece que "a formação para as relações sociais de produção ganhará um lócus específico: a escola de massas" $\left(\right.$ LIMA FILHO, 2010) ${ }^{19}$. Nestes termos, o Estado, nas sociedades capitalistas, é controlado diretamente pela classe burguesa. Marx certamente entendeu a natureza classista da escola em todos os níveis do sistema educacional ${ }^{20}$.

19 Documento sem paginação.

20 Cf. CARNOY, Martin. Educação, economia e Estado: base e superestrutura; relações e mediações. Tradução de Dagmar M. L. Zibas. São Paulo: Cortez, 1984, p. 22-23.

\begin{tabular}{|l|c|c|c|c|}
\hline Qevista Dialectus & Ano 9 & n. 19 & Agosto-Dezembro 2020 & p. $93-113$ \\
\hline
\end{tabular}




\section{Considerações finais}

A técnica e a tecnologia na sociedade capitalista, a qual carrega consigo uma oposição inconciliável entre capital e trabalho, têm o seu emprego em favor dos interesses da produção e reprodução do capital, dado que os interesses exclusivos, na formação social capitalista, são sempre os da burguesia que é a sua classe dominante, econômica e politicamente.

O sistema educacional tem, através da competência do Estado, na forma de norteadora daquele, em sendo ele (o Estado) o mediador entre a estrutura produtiva material da sociedade e os seus elementos ideológicos - como é o caso da educação -, a função decisiva de ser um dos elos responsáveis pela reprodução da autovalorização do capital, quando a educação escolar efetua a preparação intelectual, prática, e psicossocial da força de trabalho disciplinada em favor do capital.

Tratamos, fundamentalmente, o fenômeno da técnica na sociedade burguesa na sua dimensão ontológica, quer dizer, sobre como ela é usada no sistema capitalista para auferir celeridade na produção e propiciar o incremento da mais-valia relativa, o que, logicamente, é vantajoso, exclusivamente, para a classe dos capitalistas, já que, assim, ela faz cair o valor da força de trabalho.

Mediante este processo, a classe trabalhadora vê-se sempre, e cada vez mais, submetida ao poder produtivo da técnica, da tecnologia e da maquinaria, as quais nunca estão a seu serviço, mas sempre a serviço dos detentores privados dos meios de produção - os burgueses capitalistas.

Sob o que é útil para a classe dos capitalistas, a produção nunca estará direcionada a fazer frente às necessidades dos produtores diretos, como já sabemos, dos trabalhadores, mas, ao contrário, está sempre em oposição a eles, pois a produção de mercadorias é toda direcionada ao mercado mundial. Isto implica a alienação dos trabalhadores aos produtos do seu próprio trabalho, na condição de que os produtos passam a controlar os seus produtores.

Há, portanto, no modo capitalista de produção, uma contradictio in adjecto, visto que a produção capitalista é essencialmente social, sendo que a apropriação é, dada a lógica imanente deste modo de produção, contraditoriamente, privada. Isso significa que a estrutura produtiva no capitalismo se apossa de todos os meios, instrumentos e materiais que possam

\begin{tabular}{|l|l|l|l|l|}
\hline Qevista Dialectus & Ano 9 & n. 19 & Agosto-Dezembro 2020 & p. $93-113$ \\
\hline
\end{tabular}


estar disponíveis em determinado momento histórico, como resultado do desenvolvimento das forças produtivas da sociedade, sendo, por conseguinte, a produção, nestas condições, essencialmente, social; porém, ainda assim, a apropriação é relativa à situação particular de cada indivíduo isoladamente, na forma de uma imposição material que se acrescenta à produção, em contradição com a apropriação, como uma contraposição dos indivíduos separados e opostos uns dos outros pela violência do poder do dinheiro.

Já no que tange, mais precisamente, à educação, vimos que o norte do modelo educacional no sistema do capital é a reprodução das condições materiais da produção e a, equivalente, manutenção dos ganhos da classe dos capitalistas. Entre os estudantes, obviamente, que sob condições sociais diferentes, condições de classe, existem diferentes maneiras de pensar; temores e esperanças; preconceitos e ilusões; simpatias, e antipatias; convicções; princípios etc. Contudo, todas as maneiras de pensar e concepções de vida estão submetidos, na sociedade de classes, às perspectivas que importam, precipuamente, à classe dominante. O que reflete na vida individual dos estudantes das classes subalternas ou subordinadas, na confluência da violência na escola, no desalento dos educandos, na exacerbação dos preconceitos etc. Enfim, como forma de usurpação da formação integral das suas subjetividades enquanto indivíduos genuinamente humanos.

Nesta medida, um estudo concreto sobre a educação, como o que oferecemos neste texto - mostrando a forma como o tecnicismo do processo do trabalho no sistema capitalista reverbera na educação escolar -, deve deixar evidente como a produção impõe aos indivíduos, particularmente aos educandos, um padrão disciplinar que interessa fundamentalmente à própria produção. Basicamente, deve-se procurar saber como se dá a mediação entre a esfera da produção e o sistema de ensino e educação, a qual, como vimos, ocorre através do Estado.

Neste diapasão, concebemos que, em sendo o Estado o elemento jurídicopolítico da sociedade capitalista competente para nortear o modelo educacional de um país, fá-lo-á, dada a sua natureza de classe ${ }^{21}$, conforme os interesses dos capitalistas. Isto requer

21 "Como o Estado nasceu da necessidade de conter o antagonismo das classes, e como, ao mesmo tempo, nasceu em meio ao conflito delas, é, por regra geral, o Estado da classe mais poderosa, da classe economicamente dominante, classe que, por intermédio dele, se converte também em classe politicamente dominante e adquire novos meios para repressão e exploração da classe oprimida. Assim, [...] o moderno Estado representativo é o instrumento de que se serve o capital para explorar o trabalho assalariado" (ENGELS, 1985, p. 193-194).

\begin{tabular}{|l|l|l|l|l|}
\hline Qevista Dialectus & Ano 9 & n. 19 & Agosto-Dezembro 2020 & p. $93-113$ \\
\hline
\end{tabular}


a legitimação, pela forma jurídica, de uma pedagogia do capital. Daí a natureza da legislação educacional repercutir a estrutura produtiva do capital.

Porém, isto implica uma contradição, porque a educação, mesmo sendo burguesa, permite a crítica. Há, aqui, pois, uma dialética. O modelo educacional institucional é postulante dos interesses do capital. Contudo, tanto os educadores quanto os educandos, defendem, em importante medida, os seus próprios objetivos. Logo, há de se considerar a luta política e o papel do sujeito histórico-revolucionário - o proletariado. Se assim não o fosse, o domínio seria total e todos os trabalhadores seriam autômatos. Na verdade, o conhecimento sistematizado, mesmo que submetido ao perigo da ideologização, suscita, quase sempre, o desejo de mudança.

Atentemos para o fato de que a educação é também uma possibilidade de fazer com que os jovens das classes subordinadas, o proletariado e toda a classe trabalhadora, tenham acesso ao conhecimento universalmente produzido, podendo vir a conhecer aspectos importantes da tradição filosófica, da ciência, das artes, enfim, das técnicas do conhecimento sistematizado. Essa é a condição intelectual mínima para a educação dos trabalhadores, tendo em vista a sua apreensão da teoria denunciadora da exploração que o capitalismo lhes impõe, a saber, a teoria marxiana. Trata-se da posse, por parte da classe trabalhadora, da munição intelectual para fazer-lhe possível empreender a luta política por sua autoemancipação. Logo, temos evidenciadas, no mundo contemporâneo, sob o qual reina a ignorância e a barbárie, a exemplo do Brasil nos dias de hoje, a atualidade da crítica e a vitalidade do pensamento de Marx.

Com efeito, intervir efetivamente na realidade sócio-histórica do homem, significa, para Marx, revolucionar radicalmente o modo de produção material da vida, isto é, superar a forma social burguesa, enquanto sociabilidade alienada que submete os indivíduos aos interesses de classe, e sofistica o vínculo social nas Constituições do Estado. Compreende-se, desta forma, o Estado como a expressão de conjunto para a dimensão da alienação humana na sociedade burguesa, sendo, portanto, necessário derrubar esse Estado para que o homem atinja a sua emancipação.

Essa fratura no devir histórico deverá ser obra da classe que sofre diretamente, sob o jugo do capitalismo, as contradições da alienação humana e que, para emancipar-se, terá de emancipar toda a humanidade, libertando-a da situação desumana à qual está submetida pelos princípios de uma prática social alienada. Deste modo, a revolução

\begin{tabular}{|l|l|l|l|l|}
\hline Qevista Dialectus & Ano 9 & n. 19 & Agosto-Dezembro 2020 & p. $93-113$ \\
\hline
\end{tabular}


proletária, que propõe o socialismo e, em consequência, o comunismo como a forma social capaz de harmonizar a existência e a essência humanas, pretende ser identificada como a revolução do gênero humano. É também por isso que, segundo afirma, pertinentemente, Mészáros, "a tarefa de transcender as relações sociais de produção capitalistas, alienadas, deve ser concebida na estrutura global de uma estratégia educacional socialista" (MÁSZÁROS, 1981, p. 261).

\section{Referências}

BOTO, Carlota. Instrução pública e projeto civilizador: o século VIII como intérprete da ciência, da infância e da escola. São Paulo: Editora Unesp, 2017.

BOURDIEU, Pierre; PASSERON, Jean-Claude. A reprodução: Elementos para uma teoria do sistema de ensino. 3. ed. Trad. Reynaldo Bairão. Rio de Janeiro: Livraria Francisco Alves Editora S.A., 1992.

CARNOY, Martin. Educação, economia e Estado: base e superestrutura; relações e mediações. Tradução de Dagmar M. L. Zibas. São Paulo: Cortez, 1984, p. 22-23.

CHAGAS, Eduardo Ferreira. Marx e os seus textos sobre educação e ensino. Palestra proferida no VI Curso de Extensão: "A Filosofia da Educação: Uma Discussão a Partir da Tradição Filosófica”, UFC, 8 jun. 2018.

. "Diferença entre alienação e estranhamento nos Manuscritos Econômico-filosófico (1844), de Karl Marx. Revista Educação e Filosofia, Uberlândia, UFU, v. 8, n. 16 p. 23-33. jul./dez. 1994.

. "O pensamento de Marx sobre a subjetividade". In: CHAGAS E. F. et. al. (Orgs.) Subjetividade e educação. Fortaleza: Edições UFC, 2012. p. 37-62.

CHAGAS, Eduardo Ferreira; QUEIROZ, Fábio José de. Da pedagogia do capital e de sua antítese: violência, (de)formação do trabalho e a luta pela formação humana, Dialectus, ano 3, n. 9, set./dez., 2016, p. 100-112.

ENGELS, Friedrich. A origem da família, da propriedade privada e do Estado. 10. ed. Trad. de Leandro Konder. Rio de Janeiro: Civilização Brasileira, 1985.

FELISMINO, Sandra Cordeiro. "Marxismo, a filosofia insuperável do nosso tempo!", In: Trabalho, educação e a crítica marxista". Fortaleza: Imprensa Universitária, 2006. p. 289306.

FORÇAS produtivas e relações de produção". HARRIS, Laurence. In: BOTTOMORE, Tom (Editor). Dicionário do pensamento marxista. Trad. Waltensir Dutra. Rio de Janeiro: Jorge Zahar Editor, 1988.

\begin{tabular}{|l|l|l|l|l|}
\hline Qevista Dialectus & Ano 9 & n. 19 & Agosto-Dezembro 2020 & p. $93-113$ \\
\hline
\end{tabular}


GT Filosofia da tecnologia e da técnica. "Apresentação". Boletim ANPOF, s/d. Disponível em: < http://anpof.org/portal/index.php/en/gt-filosofia-da-tecnologia-e-da-tecnica >. Acesso em: $27 /$ abr. 2020.

HARVEY, David. Os limites do capital. Trad. Magda Lopes. São Paulo: Boitempo, 2013.

LIMA FILHO, Domingos Leite. "Educação técnica e educação tecnológica". In: OLIVEIRA D. A. et. al. Dicionário: trabalho, profissão e condição docente. Belo Horizonte: UFMG/Faculdade de Educação, 2010. CD-ROM.

MARX, Karl. Instruções para os delegados do conselho geral provisório: as diferentes questões. Tradução de José Barata Moura. Moscovo: Edições Progresso Lisboa, 1982. Disponível em: <https://www.marxists.org/portugues/marx/1866/08/instrucoes.htm>. Acesso em: 06 dez. 2018. 1989.

. Manuscritos económico-filosóficos. Tradução de Artur Morão. Lisboa: Edições 70,

"Para a crítica da economia política". In: Manuscritos econômico-filosóficos e outros textos escolhidos. Tradução de Edgar Malagodi. São Paulo: Abril Cultural, 1978. p. 107-140.

. O capital: crítica da economia política. Livro Primeiro (v. 1 e 2); “O processo de produção do capital". Tradução de Reginaldo Sant'Anna. Rio de Janeiro: Civilização Brasileira, 2006.

MÉSZÁROS, István. Marx: a teoria da alienação. Trad. Waltensir Dutra. Rio de Janeiro: Zahar Editores, 1981.

MORA, José Ferrater. Dicionário de filosofia - Tomo I (A - D) Trad. Maria Stela Gonçalves et. al. São Paulo: Edições Loyola, 2000.

NASCIMENTO, João Bosco Brito do. A emancipação humana no jovem Marx: o Estado e a história. Dissertação de Mestrado, João Pessoa, UFPB, Departamento de Filosofia, 1998.

. A violência na sociedade e na educação em Marx e Engels. Tese de Doutorado. Fortaleza, UFC, Departamento de Educação, 2019.

RANIERI, Jesus. Alienação e estranhamento: a atualidade de Marx na crítica contemporânea do capital. s/d. Disponível em: $<$ http://biblioteca.clacso.edu.ar/ar/libros/cuba/if/marx/documentos/22/Alienacao\%20e\%20 estranhamento....pdf>. Acesso em: 05 mai./2020.

ROMERO, Daniel. Marx e a técnica: um estudo dos manuscritos de 1861-1863. São Paulo: Expressão Popular, 2005.

\begin{tabular}{|l|l|l|l|l|}
\hline Qevista Dialectus & Ano 9 & n. 19 & Agosto-Dezembro 2020 & p. $93-113$ \\
\hline
\end{tabular}


SANTOS NETO, Artur Bispo dos. Universidade, ciência e violência de classe. São Paulo: Instituto Lukács, 2014. 